\title{
Validação de metodologias ativas de ensino-aprendizagem na promoção da saúde alimentar infantil
}

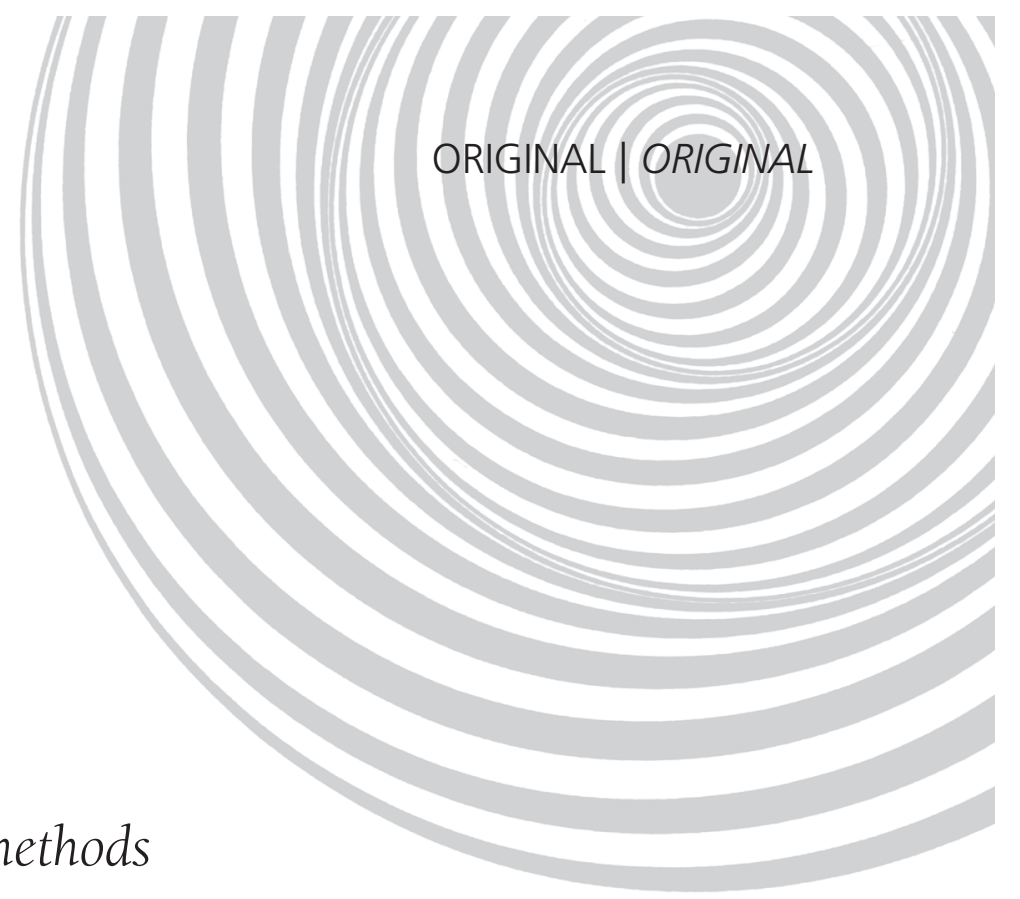

\author{
Validation of active teaching-learning methods \\ for promoting healthy eating habits \\ in schoolchildren
}

Evanira Rodrigues MAIA ${ }^{1}$

José Ferreira LIMA JUNIOR ${ }^{2}$

Jamelson dos Santos PEREIRA ${ }^{3}$

Aryanderson de Carvalho $\mathrm{ELOI}^{3}$

Camilo das Chagas GOMES 3

Marina Maria Fernandes NOBRE ${ }^{3}$

RE S U M O

\section{Objetivo}

Este estudo teve como objetivo descrever a validação de metodologias ativas de educação em saúde, na promoção da alimentação saudável de crianças do Ensino Fundamental.

\section{Métodos}

Foi feito estudo de validação de quatro tecnologias educacionais: dinâmicas de avaliação, minuto-cinema, momento-teatro e caixa dos sentidos. A pesquisa foi efetuada em 2009, com 25 crianças de 5 a 7 anos, estudantes de uma escola privada em Juazeiro do Norte, Ceará, selecionadas intencionalmente para participar de oficinas de ensino-aprendizagem. O projeto foi realizado por estudantes da Faculdade de Enfermagem daquela cidade, após aprovação do Comitê de Ética competente, e consentimento dos responsáveis pelas crianças.

\section{Resultados}

Validaram-se as metodologias utilizadas. Nas dinâmicas de avaliação, a colagem adequada dos alimentos foi realizada por $84 \%$ das crianças, demonstrando aquisição de saberes a partir da interação com os meios de comunicação, o aprendizado nutricional em família e o convívio social infantil, para a diferenciação entre alimentos saudáveis e não saudáveis. Na atividade minuto-cinema, os escolares demonstraram interesse na

\footnotetext{
${ }^{1}$ Universidade Regional do Cariri, Departamento de Enfermagem. R. Cel. Antonio Luiz, 1161, Pimenta, 63100-000, Crato, CE,

Brasil. Correspondência para/Correspondence to: ER MAIA. E-mail: <evanira@bol.com.br>.

2 Universidade Federal de Campina Grande, Escola Técnica de Saúde de Cajazeiras. Cajazeiras, PB, Brasil.

${ }^{3}$ Faculdade de Juazeiro do Norte. Juazeiro do Norte, CE, Brasil.
} 
80 ER MAIA et al.

obtenção de conhecimento sobre a valia dos alimentos abordados. No momento-teatro, observou-se interatividade eficaz entre sujeitos e pesquisadores. Todas as crianças identificaram os alimentos ocultos na caixa dos sentidos, através de sua textura e consistência, o que contribuiu para o aperfeiçoamento das habilidades cognitivas infantis. Observou-se dificuldade dos pais e da escola em ofertar alimentos saudáveis.

\section{Conclusão}

As metodologias utilizadas favoreceram o desenvolvimento de competências dos estudantes na promoção da saúde. No cuidado à criança, a alimentação é fundamental para promoção da saúde, pois o significado do ato de nutrir ultrapassa o mero ato biológico.

Termos de indexação: Educação em saúde. Promoção da saúde. Recomendações nutricionais. Saúde da criança. Saúde publica. Tecnologia.

\section{A B S T R A C T}

\section{Objective}

This study described the active teaching-learning validation methods of health education that promote healthy eating habits in elementary schoolchildren.

\section{Methods}

A validation study of four educational methods was done. They included assessment dynamics, movie minute, theater moment and sensory box. The study was done in 2009 with 25 children aged 5 to 7 years attending a private school in Juazeiro do Norte, Ceará. They were deliberately chosen to participate in teaching-learning workshops. The project was done by students from the local nursing school and approved by the local Research Ethics Committee. The children's parents or caregivers signed a free and informed consent form.

\section{Results}

The methods were validated. In the assessment dynamics, $84 \%$ of the students placed the foods correctly, showing that they learned to distinguish healthy from unhealthy foods by interacting with the communication media and from family nutrition education and child socialization. In the movie minute activity, the children demonstrated interest in learning about the value of the studied foods. There was efficient interaction between the children and researchers during the theater moment. All children identified the foods hidden in the sensory box based on their texture and consistency, which helped to improve their cognitive skills. It was difficult for the parents and school to provide healthy foods.

\section{Conclusion}

The used methods helped the students to develop their competences on health promotion. In caring for children, food is critical for good health, since nurturing is more than just a biological act.

Indexing terms: Health education. Health promotion. Nutrition policy. Child health. Public health. Technology.

\section{N T R O D U ÇÃ O}

No cuidado à saúde da criança, a alimentação é um aspecto fundamental para a promoção da saúde. Porém, a nutrição e as práticas alimentares são aprendizados sociais, não podendo ser abordadas por uma única perspectiva disciplinar, pois o significado do ato de nutrir e de comer ultrapassa o mero ato biológico. Conceitualmente, práticas alimentares referem-se à seleção dos alimentos e seu consumo, bem como ao modo de preparo das refeições e à consequente ingesta 1 .
As práticas alimentares devem ser compreendidas não somente quanto aos alimentos habitualmente consumidos, mas também quanto às condições que favorecem tais hábitos. Elas são determinadas por vários fatores, como disponibilidade objetiva dos alimentos, influências culturais, modo de vida e introdução de novos alimentos por meio da mídia, entre outros².

A promoção da alimentação saudável na infância estimula a adesão a um estilo de vida conducente com um adequado desenvolvimento cognitivo, bem como corrobora a prevenção de 
doenças crônicas não-transmissíveis ${ }^{3}$. Ao considerar que na infância ocorre a formação do hábito alimentar, sendo necessário o entendimento dos seus fatores determinantes, torna-se possível a implantação de processos educativos efetivos para a mudança do padrão alimentar da criança4.

O comportamento alimentar da criança é determinado em primeira instância pela família, da qual ela é dependente e, secundariamente, por suas outras interações psicossociais e culturais. Assim, o desafio consiste em motivar a criança a aceitar uma alimentação variada, levando-a a ampliar suas preferências e adquirir hábitos alimentares mais saudáveis ${ }^{5-7}$.

Nessa perspectiva, o ato de promover saúde na escola perpassa pela atuação concomitante de três grandes áreas: ambiente saudável, participação dos serviços de saúde e educação em saúde ${ }^{8,9}$. Logo, o ambiente escolar tem-se configurado como espaço privilegiado para o desenvolvimento de ações de melhoria das condições de saúde e do estado nutricional das crianças ${ }^{10,11}$, pois é um setor estratégico para a concretização de iniciativas de educação em saúde e coadunase com o conceito de "Escola Promotora da Saúde"12.

No entanto, o espaço escolar carece do emprego de tecnologias educacionais efetivas que favoreçam a aprendizagem ativa sobre hábitos alimentares saudáveis. A construção de metodologias educacionais pode ser considerada como composta por tecnologias leveduras, pois não só se constitui de saberes estruturados que incorporam aspectos relacionais típicos das tecnologias leves, mas também envolve equipamentos tecnológicos característicos das tecnologias duras ${ }^{13,14}$.

Ressalte-se que o uso de tecnologias apropriadas, como meio para prover saúde, é primordial ao desenvolvimento de competências educacionais. Portanto, a criação de estratégias de ensino-aprendizagem para crianças deve primar pela ativação dos conhecimentos prévios dos discentes e estar embasada em atividades lúdicas e contextualizadas. As tecnologias de educação em saúde devem ser desenvolvidas na perspectiva de serem utilizadas em diversos contextos de ensino e, para tanto, devem ser devidamente testadas para que possam cumprir seu papel educacional ${ }^{15,16}$.

Em face do contexto, objetivou-se descrever o processo de validação de metodologias ativas de ensino-aprendizagem na promoção da saúde de crianças do Ensino Fundamental, com vistas ao desenvolvimento de competências para a prática de hábitos alimentares saudáveis.

\section{MÉ T O D O S}

Este trabalho apresenta um estudo de validação de tecnologia educacional, realizado no primeiro semestre de 2009, com crianças da educação infantil de uma escola privada, localizada na cidade de Juazeiro do Norte, situada no interior do estado do Ceará, Brasil.

O estudo resultou de um projeto de integração de dois componentes curriculares: Educação em Saúde e Eixo Interdisciplinar, do curso de Enfermagem, da Faculdade de Juazeiro do Norte. A proposta pedagógica interdisciplinar objetivou também o desenvolvimento de competências de graduandos de Enfermagem na promoção da saúde.

Realizou-se revisão de literatura nacional acerca das metodologias ativas de ensino-aprendizagem, compatíveis com desenvolvimento infantil de crianças na faixa etária de cinco a sete anos de idade, em que foram analisadas oito metodologias de educação em saúde. Foram selecionadas cinco metodologias e validadas quatro, visto que uma delas requeria espaço físico maior que o disponibilizado pela escola. As atividades educativas foram aplicadas e validadas junto ao grupo de crianças no decorrer de três encontros, previamente agendados junto à coordenação e docentes.

O projeto obteve parecer favorável do Comitê de Ética em Pesquisa da Faculdade de Medicina de Juazeiro do Norte, processo $n^{\circ}$ 2009_0354/FR_25112. Após, solicitou-se auto- 
rização junto à direção da escola na qual o estudo foi realizado, bem como dos pais ou responsáveis, mediante assinatura do Termo de Consentimento Livre e Esclarecido.

Foram selecionadas 25 crianças, por meio da amostragem não probabilística intencional, as quais se encontravam na faixa etária requerida pelo estudo para testagem das metodologias ativas de ensino-aprendizagem, construídas para educação e promoção da alimentação saudável em crianças do Ensino Fundamental. A escolha justifica-se pelo fato de o Ensino Fundamental ser um momento de passagem do estudante da Educação Infantil, no qual a oferta de alimentos abandona o hábito de lancheiras organizadas em domicílio pelos pais e cuidadores, passando a serem eles comprados nas cantinas das escolas.

Os dados foram coletados por meio da observação das atividades desenvolvidas e anotadas em diário de campo, bem como pela filmagem e fotografia do transcurso da pesquisa e dos resultados obtidos, nos momentos de construção e aplicação das metodologias, dinâmicas e jogos dos quais as crianças foram convidadas a participar. Procedeu-se à análise através da descrição das atividades desenvolvidas, conforme os objetivos propostos, à luz da literatura científica atual, que amparou a discussão dos resultados.

\section{RES U L T A D O S}

A implantação das atividades e dinâmicas educativas junto ao público infantil correspondeu à existência de três momentos distintos na escola: no primeiro, desenvolveu-se um pré-teste que possibilitou a verificação inicial da percepção dos estudantes acerca de uma alimentação saudável. No segundo, fez-se uso das atividades aqui denominadas minuto-cinema e momento-teatro, em que se promoveu um diálogo sobre os riscos de uma alimentação pautada em doces e guloseimas. No terceiro encontro, via metodologia intitulada caixa dos sentidos, discorreu-se sobre o papel das frutas e legumes na alimentação humana.
Desse modo, as seguintes metodologias ativas de ensino-aprendizagem foram submetidas a processo de validação:

\section{Dinâmica de avaliação}

A dinâmica de grupo de avaliação foi confeccionada a partir de materiais didáticos de fácil acesso, tais como papel, madeira, cartolina e gravuras condizentes com a noção de alimentação adequada.

A dinâmica desenvolveu-se com a colagem de figuras de alimentos em dois painéis, em local propício à visualização: o primeiro deles destinado à colagem de figuras de alimentos saudáveis, e o segundo, de alimentos inadequados à saúde (Figura 1). Em seguida, as crianças realizaram a colagem em seus respectivos locais, conforme sua percepção alimentar, sem influência dos pesquisadores.

Observou-se que, do total de 25 crianças, $84 \%$ efetivaram a colagem adequada dos alimentos, demonstrando assim a aquisição de saberes a partir da interação com os meios de comunicação, o ensino familiar nutricional e o convívio social infantil. No entanto, $16 \%$ não obtiveram sucesso na diferenciação entre alimentos saudáveis e não saudáveis.

\section{Minuto-cinema}

A atividade minuto-cinema efetivou-se com a reunião das crianças em um auditório da unidade escolar, cujo material audiovisual permitiu a apresentação de um vídeo sobre o valor nutricional das frutas e verduras para o adequado desenvolvimento infantil, por meio de canções (Figura 2).

Verificou-se que as crianças demonstraram interesse na obtenção de conhecimento sobre a valia dos alimentos abordados, o que corroborou o enriquecimento desse momento de ensino-aprendizagem. Assim, propiciou-se oportunidade 
Objetivos de aprendizagem

Avaliar os conhecimentos prévios do grupo infantil sobre hábitos alimentares saudáveis.
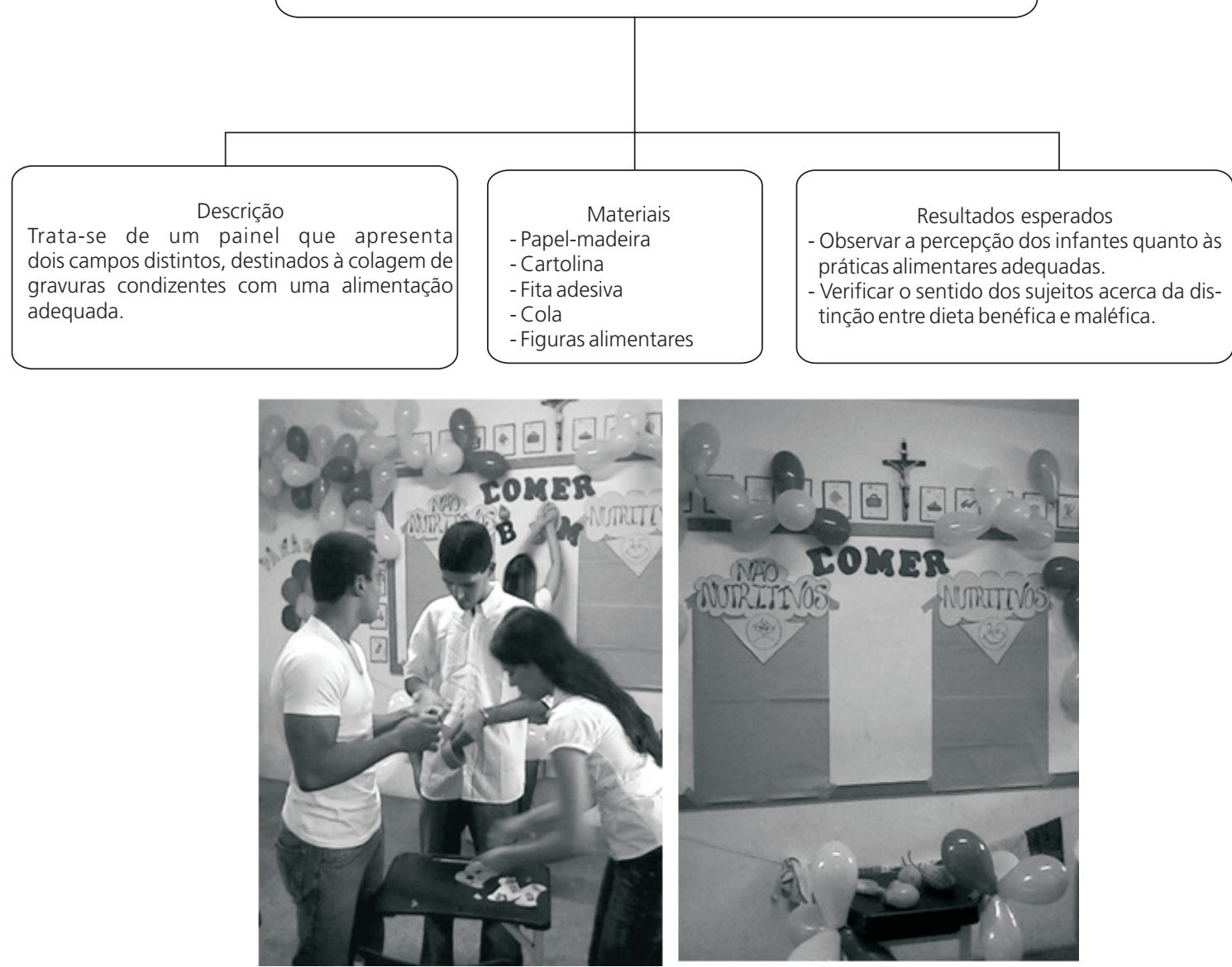

Figura 1. Metodologia ativa de ensino-aprendizagem na promoção da saúde alimentar infantil. Dinâmica de Avaliação. Juazeiro do Norte (CE), 2009

para que os participantes adquirissem saberes que possibilitassem sua adesão a uma nutrição baseada em alimentos adequados a seu desenvolvimento neuropsicomotor.

\section{Momento-teatro}

Construiu-se a metodologia momento-teatro mediante a leitura e interpretação do conto infantil "Joãozinho e Maria", seguida da elaboração de uma peça teatral adaptada ao público do estudo. Os personagens (Joãozinho, Maria e bruxa) foram representados pelos próprios pesquisadores, com o cenário composto por casa dos doces, mesa das guloseimas e floresta encantada (Figura 3).

A dinâmica desenrolou-se no próprio campo de pesquisa, conforme os seguintes passos: no início da peça, a bruxa enfatizou os prazeres proporcionados pela ingesta de doces e guloseimas, o que motivou a traçar estratégias que permitiram a Joãozinho e a Maria aderir a tal dieta. Em seguida, estes entraram em cena, atraídos por doces espalhados no decorrer de uma trilha; no trajeto, eles ingeriram grande quantidade de guloseimas. No fim do caminho, constataram que se tratava de uma armadilha da bruxa, com vistas ao surgimento de cáries dentárias, associadas à 


\section{Descrição}

Trata-se da exposição de um vídeo que retrata-se o papel das frutas e verduras no desenvolvimento infantil.

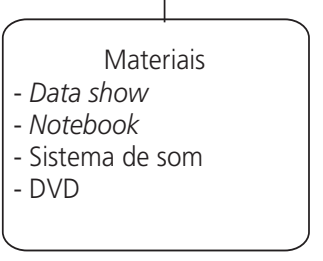

Resultado esperados
- Discutir a qualidade dos diversos grupos de
alimentos
- Desenvolver competência para os estudantes
de enfermagem
- Realizar atividades lúdicas
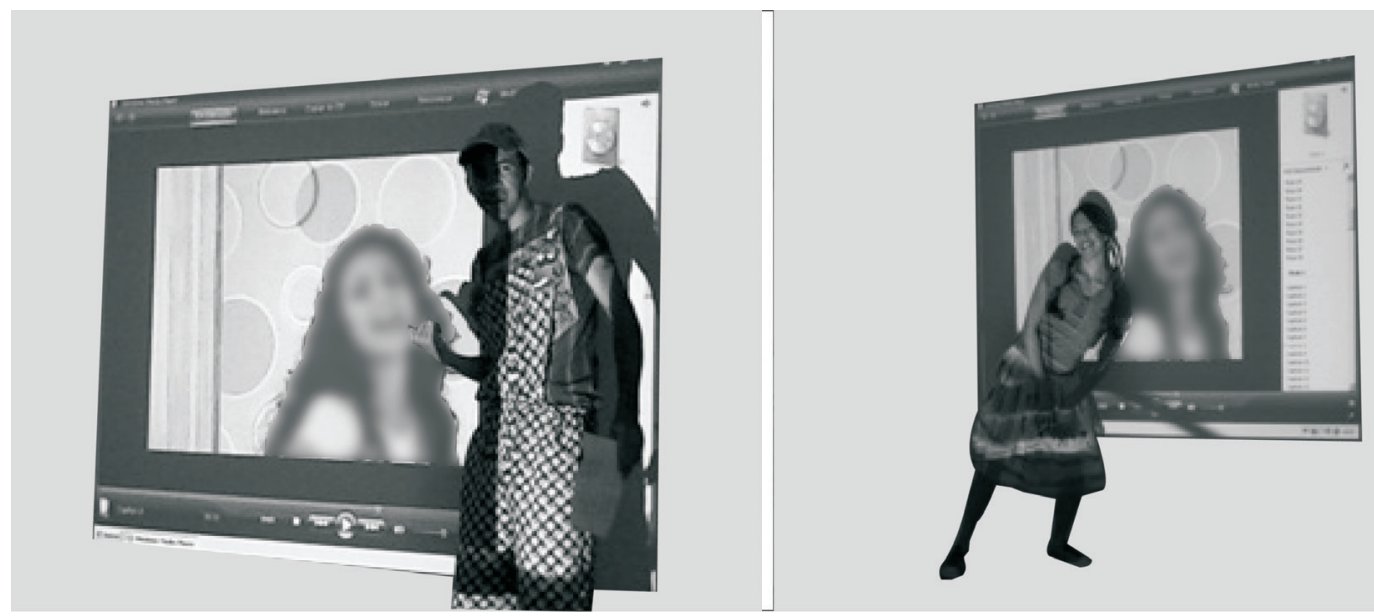

Figura 2. Metodologia ativa de ensino-aprendizagem na promoção da saúde alimentar infantil. Minuto-Cinema. Juazeiro do Norte (CE), 2009 .

odontalgia e à afagia. Por fim, Joãozinho e Maria esclareceram a bruxa acerca dos maléficos oriundos dessa nutrição e dos benefícios de uma dieta baseada em frutas e verduras.

Constou-se um resultado positivo, considerando a temática abordada, que enfatizou os males de uma alimentação baseada em doces e guloseimas, bem como a interação e aprendizagem entre sujeitos e pesquisadores, proporcionada via atividade.

\section{Caixa dos sentidos}

A estratégia caixa dos sentidos consistiu na criação de uma urna de madeira, com estam- pas ilustrativas, destinadas a enfatizar a importância das frutas e verduras. Foi adquirida uma caixa esquematizada, bem como uma variedade de frutas e verduras típicas da agricultura nordestina.

A dinâmica desenvolveu-se com a colocação da urna em local visível ao público, seguida da introdução dos alimentos em questão. Os participantes foram estimulados, um a um, por meio do sentido tátil, a descobrir o alimento contido na urna. No final da dinâmica, discorreu-se sobre o valor nutricional dos mesmos na alimentação humana, assim como sua valia nutricional (Figura 4).

Observou-se que as crianças, na sua totalidade, obtiveram êxito em identificar o alimento 
Objetivos de aprendizagem

Demonstrar os malefícios atrelados à ingesta excessiva de doces e guloseimas.
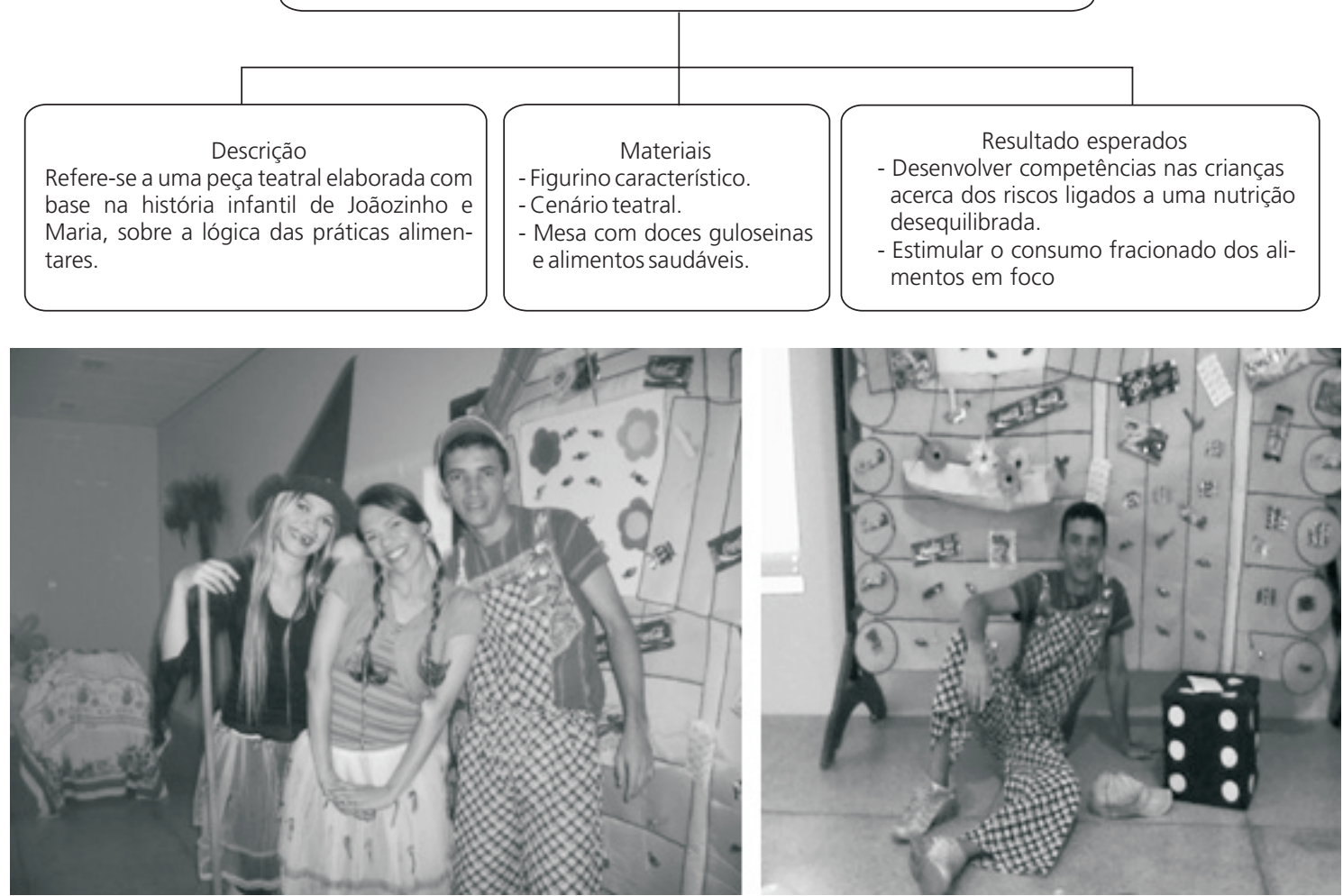

Figura 3. Metodologia ativa de ensino-aprendizagem na promoção da saúde alimentar infantil. Momento-Teatro. Juazeiro do Norte (CE), 2009.

oculto, por meio de sua textura e consistência. Consequentemente, acredita-se que a dinâmica contribuiu para o aperfeiçoamento das habilidades cognitivas infantis, bem como para a melhoria da compreensão acerca do papel das frutas e verduras na alimentação.

\section{I S C U S S Ã O}

Na validação das metodologias de ensino-aprendizagem, primou-se por iniciar com uma dinâmica de avaliação. Esta revelou que, das oito metodologias analisadas, três mostraram-se inadequadas à faixa etária das crianças deste estudo, porque tratavam de atividades relacionadas à educação sexual de jovens do Ensino Médio.
Na Educação Infantil, é central avaliar o desenvolvimento do padrão alimentar da criança, o qual é estabelecido pelo processo de condicionamento, pela associação da sugestão sensória dos alimentos, pela consequência pós-ingesta da alimentação e pelo contexto social alimentar em que ela está inserida ${ }^{17}$. São diversificados os contextos em que os grupos sociais criam suas estratégias de construção de saber ${ }^{18}$. O aprendizado, no caso específico da alimentação, é construído desde a infância, através do contato com os membros familiares e com a comunidade. É essencial para o desenvolvimento da criança uma alimentação qualitativa e quantitativamente adequada, pois esta proporciona ao organismo a energia e os nutrientes necessários para o bom 

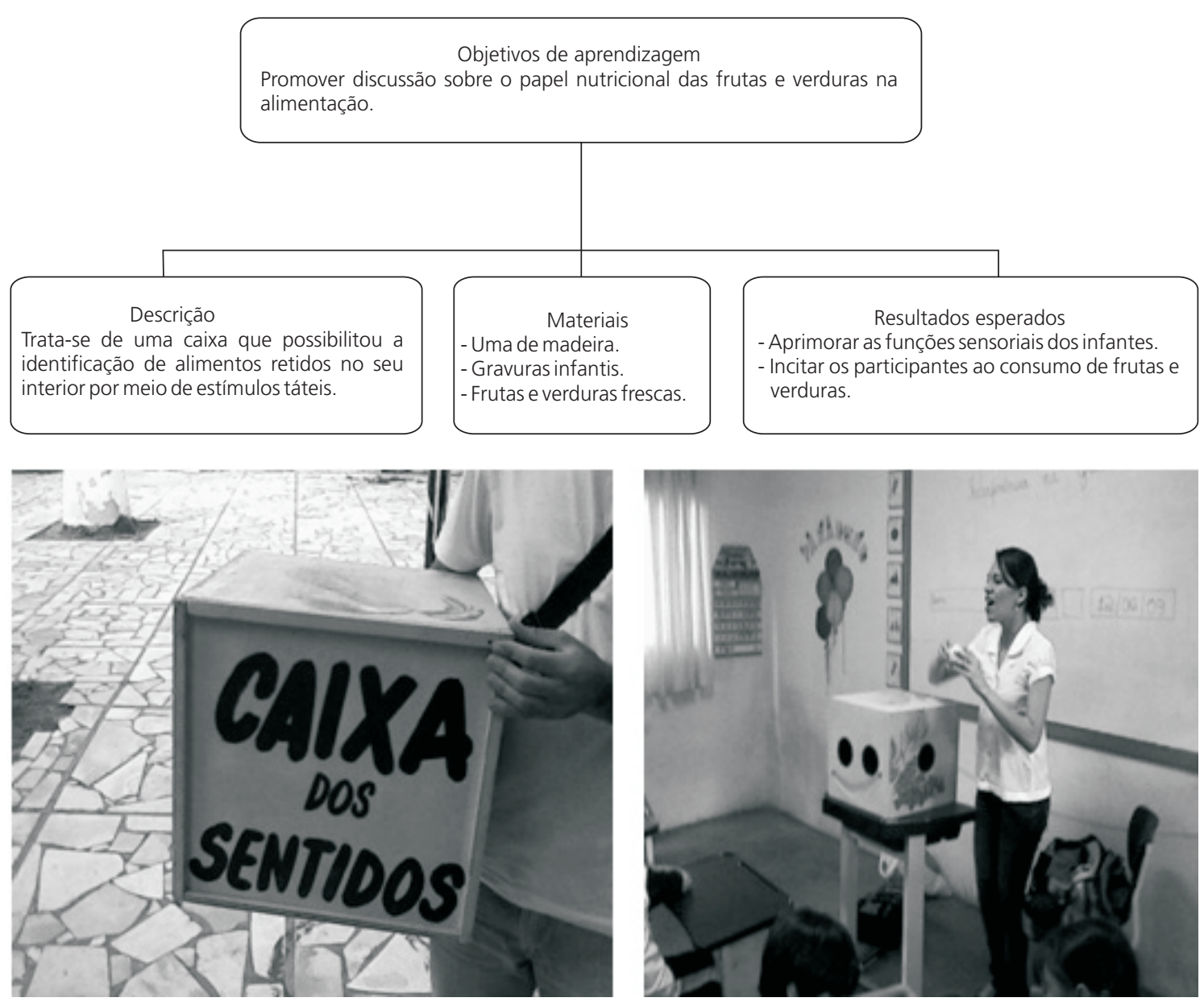

Figura 4. Metodologia ativa de ensino-aprendizagem na promoção da saúde alimentar infantil. Caixa dos sentidos. Juazeiro do Norte (CE), 2009.

desempenho de suas funções e a manutenção de um bom estado de saúde ${ }^{19}$.

Para conduzir de forma apropriada a alimentação da criança, o processo educacional requer estratégias relacionadas aos aspectos sensoriais (apresentação visual, cores, formatos, atrativos), proporcionadas de modo lúdico. A educação nutricional possibilita compreender a forma de preparo dos alimentos, as porções oferecidas e o ambiente em que ocorrem as refeições, que são fatores importantes para a satisfação das necessidades nutricionais, emocionais e sociais, e para a promoção de uma qualidade de vida saudáve $\left.\right|^{20}$.
O período escolar é tido como um momento estratégico para a materialização de orientações nutricionais ativas e participativas, pois possibilita a incorporação de novos hábitos alimentares e o conhecimento de novos sabores, texturas e cores - experiências sensoriais que influenciarão diretamente no padrão alimentar a ser adotado pelo infante ${ }^{21}$. Nesse sentido, entende-se que o minuto-cinema favoreceu a aquisição de competências para tal. De outro lado, para proporcionar aos estudantes conhecer os riscos e as consequências da dieta inadequada, utilizou-se o momento-teatro, no qual se propôs a redução do consumo de guloseimas, presentes no cenário de "Joãozinho e Maria", bem como a eleva- 
ção da ingesta de nutrientes propícios a um desenvolvimento cognitivo satisfatório.

Entende-se por educação em saúde um processo crítico e transformador, no qual se insere um agente promotor de comunicação, que proporciona um aprendizado de caráter individual ou coletivo, além de uma mudança de comportamento, antes desfavorável e de vulnerabilidade à saúde ${ }^{22}$. A promoção da saúde é entendida como um conjunto de atividades que capacitam um indivíduo ou um grupo social a desenvolver os recursos necessários para manter ou elevar seu bem-estar, refletindo-se na sua qualidade de vida22.

A oferta de um processo ativo e dinâmico, no qual indivíduo e grupos sociais sejam incentivados a ser responsáveis pela mudança de hábitos e aumento do seu bem-estar, incorporando a importância e o impacto das dimensões socioeconômicas, políticas e culturais sobre as condições de saúde, reconhecendo ainda que a promoção desta não se limita exclusivamente ao setor saúde, constitui atividade eminentemente intersetorial23.

São válidas as ferramentas de orientação que visam à promoção da saúde por meio da formação de hábitos alimentares adequados e adaptados aos conhecimentos científicos; são válidas as recomendações nutricionais e de composição alimentar, com mensagens práticas que facilitem, ao maior número de pessoas, a seleção e o consumo adequados de alimentos, levando em consideração os fatores antropológicos, culturais, educativos, sociais e econômicos ${ }^{24}$. Tais ferramentas necessitam ser compreendidas e utilizadas como meio didático na operacionalização do processo de educação nutricional. O seu destinatário é a garantia da comunicação quando o desejo é democratizar o saber em alimentação e nutrição ${ }^{24}$. Nesse sentido, o minuto-cinema teve como propósito favorecer a aquisição desses conhecimentos, habilidades e atitudes.

\section{CONCLUSÃ O}

As estratégias implementadas possibilitaram o aprendizado mútuo entre sujeitos e pesquisadores acerca de hábitos alimentares saudáveis e sua valia ao adequado desenvolvimento infantil. As crianças mostraram-se motivadas a incorporar saberes sobre a nutrição adequada, tendo em vista a redução dos riscos de doenças cardiovasculares.

Ademais, o emprego de metodologias ativas de ensino-aprendizagem favoreceu o desenvolvimento de competências dos discentes de enfermagem envolvidos na educação e promoção da saúde infantil, possibilitando-Ihes uma abordagem eficaz e coerente com o papel de futuros profissionais de saúde.

\section{COLABORADORES}

ER MAIA, JF LIMA JUNIOR e JS PEREIRA participaram da concepção, desenho, execução, análise e interpretação, bem como da escrita e revisão final do manuscrito, na qualidade de orientadora. AC ELOI, CC GOMES, AF FREITAS e MMF NOBRE participaram da elaboração, desenho e execução do projeto.

\section{REFERÊ N CIAS}

1. Rotenberg S, Vargas S. Práticas alimentares e o cuidado da saúde: da alimentação da criança à alimentação da família. Rev Bras Saúde Mater Infant. 2004; 4(1):85-94. doi: 10.1590/S151938292004000100008 .

2. Catrib AMF, Pordeus AMJ, Ataíde MBC, Albuquerque VLM, Vieira NFC. Saúde no espaço escolar. In: Barroso GT, Vieira NFC, Varela ZMV, organizadores. Educação em saúde no contexto da promoção humana. Fortaleza: Demócrito Rocha; 2003.

3. Bernardon R, Silva JRM, Cardoso GT, Monteiro RA, Amorim NFA, Schmitz BAS, et al. Construção de metodologia de capacitação em alimentação e nutrição para educadores. Rev Nutr [Internet]. 2009 [acesso 2010 dez 1]; 22(3):389-98. Disponível em: <http://www.scielo.br>. doi: 10.1590/S1415-52 732009000300009.

4. Angelis RC. Alimentação na infância vs conseqüências ulteriores na saúde. Rev Paul Pediatr. 1995; 13(4):126-7. 
5. Rozin P. Sociocultural influences on human food selection. In: Capaldi ED. Why we eat what we eat: the psychology of eating. $2^{\text {nd }} \mathrm{ed}$. Washington (DC): APA; 1997.

6. Birch LL. Psychological influences on the childhood diet. J Nutr. 1998; 128(2):407-10.

7. Lefrève $F$, Lefrève $A M C$. Promoção de saúde: a negação da negação. Rio de Janeiro: Vieira \& Lent; 2004.

8. Organización Panamericana de la Salud. Promoción y educación de la salud escolar, una perspectiva integral: marco conceptual y operativo. Washington (DC): OPAS; 1995.

9. Mahan LK, Escott-Stumpp S. Alimentos, nutrição e dietoterapia. Rio de Janeiro: Roca; 2005.

10. Ramos M, Stein LM. Desenvolvimento do comportamento alimentar infantil. J Pediatr. 2000; 76(Suppl 3):228-37.

11. Gonçalves FD, Catrib AMF, Vieira NFC, Vieira LJES. A promoção da saúde na educação infantil. Interface [Internet]. 2008 [acesso $2010 \mathrm{dez}$ 10]; 12(24):181-92. Disponível em: <http://www.scielo. br>. doi: 10.1590/S1414-32832008000100014.

12. Spyrides MHC, Struchiner CJ, Barbosa MTS, KaC G. Efeito das práticas alimentares sobre o crescimento infantil. Rev Bras Saude Mater Infant [Internet]. 2005 [acesso 2010 dez 11]; 5(2):145-53. Disponível em: <http://www.scielo.br>. doi: 10.15 90/S1519-38292005000200002.

13. Merhy EE. Em busca de ferramentas analisadoras das tecnologias em saúde: a informação e o dia a dia de um serviço, interrogando e gerindo trabalho em saúde. In: Merhy EE, Onoko R, organizadores. Agir em Saúde: um desafio para o público. São Paulo: Hucitec; 2002.

14. Nietsche EA. Tecnologia emancipatória: possibilidades para a práxis de enfermagem. São Paulo: Unijuí; 2000.
15. Colliere EM. Prover a vida: da prática das mulheres de virtude aos cuidados de enfermagem. Lisboa: Lidel Edições Técnicas; 1999.

16. Birch $L L$, Fischer JA. The role of experience in the development of children's eating behavior. In: Capaldi ED. Why we eat what we eat: the psychology of eating. $2^{\text {nd }}$ ed. Washington (DC): APA; 1997.

17. Vargas SM. Fundamentos teóricos para a compreensão da formação e aprendizagem de leigas no campo. Rev Fac Educ. 2000; (2):94-106.

18. Rodriguez NR. Optimal quantity and composition of protein for growing children. J Am Coll Nutr. 2005; 24(2):150-4.

19. Philippi ST, Cruz ATR, Colucci ACA. Pirâmide alimentar para crianças de 2 a 3 anos. Rev Nutr [Internet]. 2003 [acesso $2010 \mathrm{dez}$ 13]; 16(1):5-19. Disponível em: <http://www.scielo.br>. doi: 10.1590/S1415-52732003000100002.

20. Alviña MW. Alimentación del preescolar y escolar menor. In: Ortiz MR, Araya HL, Samur EA, Alvarez DS. Nutrición y salud. Santiago: Universidad de Chile; 1996.

21. Barroso GT, Vieira NFC, Varela ZMV. Educação e saúde no contexto da produção humana. Fortaleza: Demócrito Rocha; 2003.

22. Vieira LJS, Barroso MGT. Conceitos de cultura; uma compreensão necessária para o cuidado de enfermagem. RECCS. 2001; 14(4):32-5.

23. Ferraz ST. Cidades saudáveis: uma urbanidade para 2000. Brasília: Paralelo 15; 1999.

24. Pena M, Palma VM. Guias de alimentación en America Latina. Anais do I Workshop Instituto Danone: alimentação equilibrada para a população brasileira; 1998. Florianópolis, Brasil. Florianópolis: Instituto Danone; 1998. p.31-43.

Recebido em: 22/2/2011

Versão final reapresentada em: 10/8/2011 Aprovado em: 27/9/2011 